\title{
ASSESSMENT OF SUMMER TRENDS OF TROPOSPHERIC RADON ISOTOPES IN A COASTAL ANTARCTIC STATION (TERRA NOVA BAY)
}

\author{
LAURA TOSITTI ${ }^{\mathrm{a}, *}$, ENIO BUENO PEREIRA ${ }^{\mathrm{b}}$, SILVIA SANDRINI $^{\mathrm{a}}$, DAVIDE \\ CAPRA $^{\mathrm{c}}$, OTTAVIO TUBERTINI ${ }^{\mathrm{a}}$ and MARIA GIOVANNA BETTOLI ${ }^{\mathrm{a}}$ \\ ${ }^{a}$ Laboratorio di Radiochimica Ambientale, Dip. di Chimica "G.Ciamician", Univ. di Bologna, \\ Bologna, Italy; ' Instituto Nacional de Pesquisas Espaciais, S.José dos Campos, Brasil; \\ ${ }^{\mathrm{c}}$ CESI S.p.A. - Segrate (MI)
}

(Received 10 January 2000; In final form 4 March 2001)

\begin{abstract}
This work reports the first results of atmospheric radon measurements performed at the Italian Antarctic station located at Terra Nova Bay $\left(74.69^{\circ} \mathrm{S} ; 164.12^{\circ} \mathrm{E}\right)$ during summer campaigns of $1995-96,1996-97$ and 1997-98. Mean ${ }^{222} \mathrm{Rn}$ concentrations was $0.51 \pm 0.43 \mathrm{~Bq} \mathrm{~m}^{-3}$ (median $=0.37 \mathrm{~Bq} \mathrm{~m}^{-3}$ ), and ranged from 0.01 to $2.74 \mathrm{~Bq} \mathrm{~m}^{-3}$. On the average, these values were considered high, in comparison to results reported for other sites in Antarctica at equivalent latitudes. This could be explained by two causes: radon data for Terra Nova Bay were only for the summer period, when the ice-free area is at its maximum and thus the radon emission to the atmosphere; and by the larger ice-free area at Terra Nova Bay compared, for example, to measurements taken at another Antarctic site by the same technique (Ferraz station $-62^{\circ} 05^{\prime} \mathrm{S} ; 058^{\circ} 23.5^{\prime} \mathrm{W}$ ). The mean ${ }^{222} \mathrm{Rn}$ to ${ }^{220} \mathrm{Rn}$ activity ratio was $4.4 \pm 4.2$, ranging between 0.1 and 45.3 . The highest ratios indicated that some of observed surges of concentration of ${ }^{222} \mathrm{Rn}$ could be attributed to not local sources. Lower radon concentrations were observed during katabatic wind events. The diurnal radon variation followed the general trend observed for continental areas located at lower latitudes.
\end{abstract}

Keywords: ${ }^{222} \mathrm{Rn} ;{ }^{220} \mathrm{Rn}$; Antarctica; Atmospheric tracers

\section{INTRODUCTION}

Transport and mixing are dynamical features of basic importance in the study of the atmospheric environment. Such processes are responsible for the redistribution on a global scale of all the energy forms and of all the atmospheric components emitted by the terrestrial surface often undergoing chemical transformations and/or precipitation scavenging.

The study of the atmospheric transport and mixing either on a local or on a global scale is based on the measurement of suitable tracers, followed by the elaboration and validation of models with experimental data.

*Corresponding author. Fax: +39-51-2099456. E-mail: laurat@ciam.unibo.it 
Natural radioactive tracers are efficient minor components used in the atmospheric investigations owing to their intrinsic properties as geochronometers following their physical decay and to their ubiquity. In spite of their extremely low chemical concentrations, they can be efficiently measured by present radiation detection techniques [1-5].

Radon gas, whose chemical inertia as a noble gas renders it indifferent to any environmental process of removal from the atmosphere, with the exception of its radioactive decay, is one of the most suitable tracers of the atmospheric dynamics. This radioelement has two main isotopes, ${ }^{222} \mathrm{Rn}\left(t_{1 / 2}=3.83 \mathrm{~d}\right)$, belonging to the ubiquitous ${ }^{238} \mathrm{U}$ family from which it is generated after a series of chain decays, and ${ }^{220} \mathrm{Rn}$ $\left(t_{1 / 2}=56 \mathrm{~s}\right)$ from the ${ }^{232} \mathrm{Th}$ series similarly diffused in all the crustal materials. Owing to its known sources, radon is suitable to study the mass exchanges between the continental Atmospheric Boundary Layer (ABL) and the free troposphere. Radon is emitted continuously to the atmospheric environment from all exposed soils and rocks by diffusion processes affected by several factors including $U$ and $T h$ geochemistry, soil porosity, moist, atmospheric pressure and temperature. The ocean contribution is estimated to be equal to $1.4 \%$ of the total emission to the atmosphere [6,7] and is therefore, negligible. Moreover, the 3.8-day half-life of ${ }^{222} \mathrm{Rn}$ matches with the time scale of most mesoscale transport and mixing processes in the troposphere.

For these reasons ${ }^{220} \mathrm{Rn}$ is often used as tracer to test vertical mixing [8,9], and ${ }^{222} \mathrm{Rn}$ for general circulation models [10]. In addition, due to its practically exclusive continental source, it has been used to evaluate the transit time and the dilution factor of air masses between continents [11-14]. This feature is especially important for the Antarctic continent which, on a first approximation, is considered to be little influenced by meridional synoptic circulation. However, the discovery of the so-called "radonic storms" has actually pointed out the active tropospheric transport of air masses from lower latitudes towards the Antarctic continental border [11,13].

Radon measurements in remote location such as Antarctica are typically scarce. Their climatological significance, connected with the present development of atmospheric modelling, constitute a key tool for the study of the role played by the Antarctic continent on the global climate [15]. In addition, radon can be employed for the characterization of local climatology, particularly when ${ }^{222} \mathrm{Rn}$ data are accompanied by the measurements of the short-lived ${ }^{220} \mathrm{Rn}$ isotope.

In this paper, radon data collected at Terra Nova Bay $\left(74.69^{\circ} \mathrm{S} ; 164.12^{\circ} \mathrm{E}\right)$, Northern Victoria Land, in the summer campaigns of 1995-96, 1996-97 and 1997-98 are compared with parallel data collected at another coastal station, the Brazilian Antarctic station Ferraz $\left(62^{\circ} 05^{\prime} \mathrm{S} ; 058^{\circ} 23.5^{\prime} \mathrm{W}\right)$ (see Fig. 1).

\section{SITE DESCRIPTION}

Terra Nova Bay, Victoria Land, is located on the Western coast of the Ross Sea, covering an area between $74^{\circ} 39^{\prime}$ and $75^{\circ} 30^{\prime}$ of latitude $\mathrm{S}$ and $162^{\circ} 30^{\prime}$ and $164^{\circ}$ of longitude. The bay is about $80 \mathrm{~km}$ wide and $30 \mathrm{~km}$ deep and is delimited by the small peninsula of Cape Washington to the North, and by the tongue of the Drygalsky glacier to the South. This area is characterised by a mountainous landscape with the volcanic Mt. Melbourne in the North, followed to the South by the Northern Foothills and several huge glaciers (Campbell, Priestley and Reeves converging into the Nansen ice sheet) and the Drigalsky deepening into the sea for about $60 \mathrm{~km}$. 


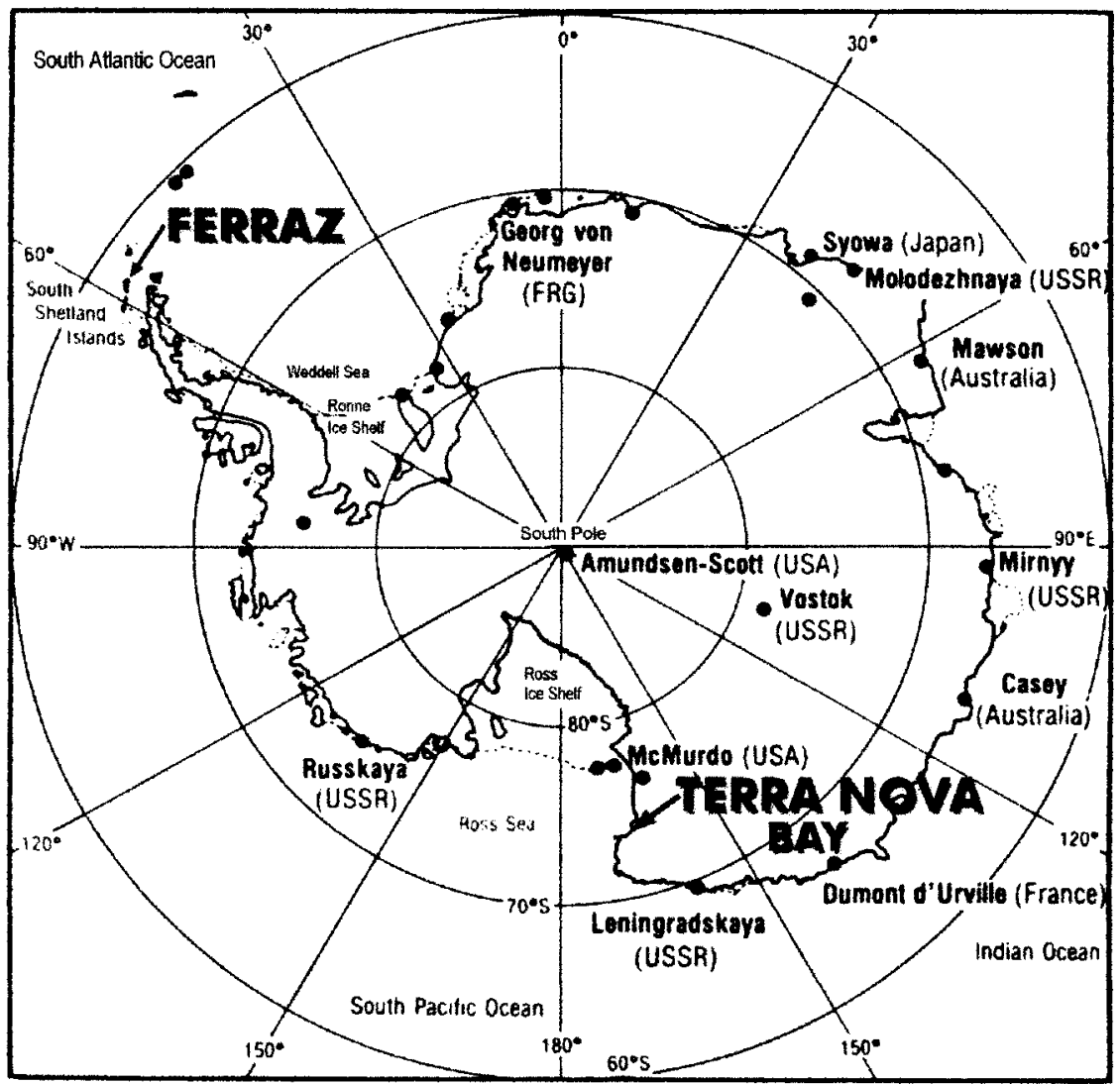

FIGURE 1 Map of the Antarctica reporting the locations of the Italian and the Brazilian stations for which radon values are compared.

Local meteorology is determined by the peculiarities of the Antarctic continent, namely geographic position, topography and morphology [16]. The basic meteorological features are the extremely high stability of the planetary boundary layer produced by the strong temperature inversion; the short duration of the austral summer (about two months); the prevalence of gravity (katabatic) winds; low relative humidity: and an atmospheric circulation dominated by the polar vortex which renders the continent a relative isolation from the lower latitudes [17].

Owing to its geographic position downwind the inner Antarctic plateau, Terra Nova Bay is characterized by a high frequency of katabatic winds channelling in the glacial valleys towards the coast with speeds up to $30 \mathrm{~m} / \mathrm{s}$ in the summer and $50 \mathrm{~m} / \mathrm{s}$ in the winter [18].

\section{EXPERIMENTAL}

Radon was measured by continuous $\alpha$-spectrometry with a device designed and manufactured at the Brazilian National Institute for Space Research (INPE) [19-21]. This method requires continuous air aspiration with a pump system coupled to a 
suitable detector. Unlike the radon monitor used in the previous campaigns, based on a modified Lucas cell, i.e. on the scintillation of alpha particles on $\mathrm{ZnS}(\mathrm{Ag})$ [22], the current instrumentation, based on the electrostatic precipitation of ${ }^{222,220} \mathrm{Rn}$ decay products followed by the instantaneous $\alpha$-spectrometry on a surface barrier Si detector, presents a better time resolution and sensitivity, and lower noise. This innovative procedure allows for the simultaneous detection of both radon isotopes even at the lowest atmospheric concentration levels found in Antarctica. Typical ${ }^{222} \mathrm{Rn}$ activity measured in Antarctica is around $0.02 \mathrm{~Bq} \mathrm{~m}^{-3}$ [23] against a mean global value of $5 \mathrm{~Bq} \mathrm{~m}^{-3}$ as reported by UNSCEAR in the lower troposphere [24].

The instrument is operated inside the Italian base facilities and the air inlet samples outdoor at a height of $3 \mathrm{~m}$ above the ground with a flowrate of $1.61 / \mathrm{min}$. As previously mentioned, radon is measured by $\alpha$-spectrometry of the daughters of both isotopes. Radon data are integrated on an hourly basis as a consequence of the low counting rates. This also provides with the possibility of performing a data screening to remove artefacts, as explained below in this text. Figure 2 depicts an integrated alpha spectrum of sampled air. Note the interference of ${ }^{212} \mathrm{Po}\left(\mathrm{E}_{\alpha}=6.02 \mathrm{MeV}\right)$ over the ${ }^{218} \mathrm{Po}$ emission $\left(\mathrm{E}_{\alpha}=6.00 \mathrm{MeV}\right)$, for which the reported branching ratio correction was applied.

One of the principal difficulties with the measurement of atmospheric radon lies on the lack of an internationally recognized calibration procedure for the measuring instruments. The main source of uncertainty in the calibration procedure is the difficulty in determining the "escape-to-production" ratio of radon relatively to ${ }^{226} \mathrm{Ra}$ by which it is generated through radioactive decay; this uncertainty is mainly related to the fact that all the radon isotopes are gaseous.

$$
\mathrm{Ra}-226 \underset{\substack{(1620 \mathrm{y}) \\
\text { (liquid, solid) }}}{\stackrel{\alpha}{\longrightarrow}} \mathrm{Rn}-222 \underset{\begin{array}{c}
(3.823 \text { days) } \\
\text { (gas) }
\end{array}}{\stackrel{\alpha}{\longrightarrow}}
$$

Though several calibration sources have been proposed and used internationally, no standardization has been accomplished to date, even by the International Atomic Energy Agency (IAEA). For ${ }^{220} \mathrm{Rn}$ no direct calibration source is available. Furthermore, owing to this lack of regulation, some results reported in literature correspond,

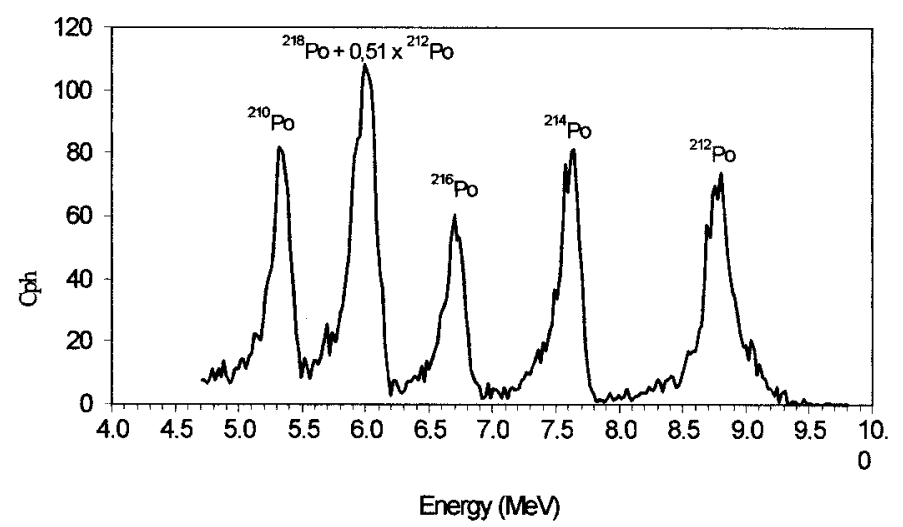

FIGURE 2 Alpha spectrum of ${ }^{222,220} \mathrm{Rn}$ progeny obtained with the electrostatic precipitator built at INPE. 
in fact, to measurement of total radon $\left({ }^{222} \mathrm{Rn}+{ }^{220} \mathrm{Rn}\right)$ rather than of the most important ${ }^{222} \mathrm{Rn}$. Our results are for independent measurements of these radon isotopes.

The equipment used in this work was calibrated against a second calibrated equipment that served as secondary standard. The secondary standard instrument was calibrated at INPE by employing a dynamic calibration technique described by Pereira [19] and Silva [7]. This procedure uses a standard ${ }^{222} \mathrm{Rn}$ emanation source (NIST SRM 4968-89 from the National Institute of Standard and Technology USA), which consists of a small porous plastic capsule containing a diluted calibrated ${ }^{226} \mathrm{Ra}$ solution inside, and a known escape-to-production ratio (Table I).

The calibration set-up was performed by flowing a carrier analytical grade nitrogen through a gas-washing bottle where the emanation source was deposited. This gas is guaranteed to be completely radon depleted owing to its purity and to a very long aging process. The radon monitor is placed at the outlet of this bottle. When steadystate between emission rate and gas flow in the system $(t \rightarrow \infty)$ is established (constant reading) radon concentration is known as a function of the flowrate $\left(\varphi\left(1 \mathrm{~min}^{-1}\right)\right)$ according to the following equation:

$$
\text { Activity of }{ }^{222} \mathrm{Rn}\left(\mathrm{Bq} \mathrm{m}^{-3}\right)=\frac{\varepsilon A}{V}\left(1+\frac{\varphi}{V_{\text {sis }} \lambda_{222}}\right)^{-1}
$$

where $V$ is the volume of the precipitation chamber $\left(\mathrm{m}^{3}\right)$; and $V_{\text {sis }}$ is the volume of the whole calibration system, including the gas washing bottle and tubing $\left(\mathrm{m}^{3}\right) ; \lambda_{222}$ is the half-life of ${ }^{222} \mathrm{Rn}\left(\mathrm{s}^{-1}\right)$. The instrumental noise, measured under strictly controlled conditions and for several days under a radon-free carrier air was equivalent to $0.0015 \mathrm{~Bq} \mathrm{~m}^{-3}$, thus well below the measured concentration in the site $\left(0.01-2.74 \mathrm{~Bq} \mathrm{~m}^{-3}\right)$. Data screening was performed by subtracting all spikes that could not be produced by radon surges and, thus, were necessarily associated to electronic noise, such as switching large inductive electric devices near the experiment, although this was a very rare event. Finally a last test for rejection of suspicious observations was applied using the well-known Chauvenet's criterion [25].

This calibration technique was cross compared with flash samples taken from a common inlet and measured by the Environmental Measurements Laboratory of the US Department of Energy in 1995 using a proportional chamber during a cross

TABLE I Characteristics of the ${ }^{222} \mathrm{Rn}$ source used for the calibration of radon equipment (NIST SRM 4968-89 from the National Institute of Standard and Technology - USA)

\begin{tabular}{lc}
\hline$S R M 4968$ & \\
\hline Total mass of ${ }^{226} \mathrm{Ra}$ & $03.323 \mathrm{~g}$ \\
Activity of ${ }^{226} \mathrm{Ra}(\mathrm{A})$ & $383.6 \mathrm{~Bq}$ \\
Uncertainty & $0.93 \%$ \\
Reference date for & Sep 9,1991 \\
${ }^{226} \mathrm{Ra}$ decay correction & $1620 \mathrm{y}$ \\
Half-life of ${ }^{226} \mathrm{Ra}$ & $0.890\left(\mathrm{at} 21^{\circ} \mathrm{C}\right)$ \\
Escape-to-production ratio $(\varepsilon)$ & $4 \%$ \\
Uncertainty in $\varepsilon$ & $3.82 \mathrm{~d}$ \\
Half life of ${ }^{222} \mathrm{Rn}$ & \\
\hline
\end{tabular}


calibration mission in the US (unpublished results by Pereira). Results from these two independent techniques did not differ more than $14 \%$ from each other.

Direct calibration for ${ }^{220} \mathrm{Rn}$ is not yet possible with this equipment. Nevertheless, an indirect estimate of this radon isotope was possible by using the approach described by Silva [7], based on the hypothesis that the electrostatic collection efficiency of the equipment is the same for both the ${ }^{218} \mathrm{Po}$ and ${ }^{216} \mathrm{Po}$. Since the above calibration procedure is exhausting and time consuming, an instrument calibrated with the above procedure is always kept in the laboratory at INPE and is employed as secondary radon standard for all other instruments constructed exactly with the same physical and electronic characteristics. The resulting activities for ${ }^{222} \mathrm{Rn}$ and ${ }^{220} \mathrm{Rn}$ are obtained respectively by the following equations:

$$
\begin{gathered}
{ }^{222} \mathrm{Rn}\left(\mathrm{Bq} \mathrm{m}^{-3}\right)=0.038 \cdot\left[(\mathrm{cpm})_{222 \mathrm{Rn}}\right]^{2}+2.0181 \cdot(\mathrm{cpm})_{222 \mathrm{Rn}} \\
{ }^{220} \mathrm{Rn}\left(\mathrm{Bq} \mathrm{m}^{-3}\right)=1.573039 \cdot(\mathrm{cpm})_{220 \mathrm{Rn}}-0.000661
\end{gathered}
$$

where $(\mathrm{cpm})_{222 \mathrm{Rn}}$ is the count rate of ${ }^{218} \mathrm{Po}$ corrected by the ${ }^{212} \mathrm{Po}$ branching ratio interference, and $(\mathrm{cpm})_{220 \mathrm{Rn}}$ is the count rate of ${ }^{216} \mathrm{Po}$. The correlation between the 4-day ${ }^{222} \mathrm{Rn}$ time series measured by these two instruments was 0.97 for air collected simultaneously and at the same inlet point. The relative root mean square error was $11 \%$ and the relative bias was negligible $(0.2 \%)$. Therefore, data presented in this work can be considered reliable for the purpose of the assessment of radon trends in the atmosphere at Terra Nova Bay area.

Radiometric characterization of soil and rock samples from Terra Nova Bay was effected by high-resolution $\gamma$-spectrometry with a HPGe $p$-type coaxial detector by ORTEC (30\% relative efficiency; FWHM $=1.95 \mathrm{keV}$ at $1332.5 \mathrm{keV}$ of $\left.{ }^{60} \mathrm{Co}\right)$ using a Marinelli beaker geometry. Samples of about $2 \mathrm{~kg}$ were counted for $80000 \mathrm{~s}$. Natural radioactivity was determined through the following lines: $186 \mathrm{keV}$ of ${ }^{226} \mathrm{Ra}$ corrected by the ${ }^{235} \mathrm{U}$ emission at the same energy, the $352 \mathrm{keV}$ of ${ }^{214} \mathrm{~Pb}, 609 \mathrm{keV}$ of ${ }^{214} \mathrm{Bi}$ for the ${ }^{238} \mathrm{U}$ family, the $239 \mathrm{keV}$ of ${ }^{212} \mathrm{~Pb}$ and the $583 \mathrm{keV}$ of ${ }^{208} \mathrm{Tl}$ corrected by the branching ratio, for the ${ }^{232} \mathrm{Th}$ family, and the $1460.8 \mathrm{keV}$ for the primordial ${ }^{40} \mathrm{~K}$.

\section{RESULTS AND DISCUSSION}

As previously described, radon is emitted by all crustal materials with modalities and diffusive fluxes, depending principally on the morphology and geochemical composition of rocks and soils. The ice cover blocks the diffusion of radon from the earth's upper layer of the crust to the atmosphere. Thus, the commonly low activity values found for radon in the Antarctic atmosphere are due to the reduced ice-free areas, which are present mainly along the coast during the summer period. In addition, soil in the cold regions is characterized by the presence of permafrost further entrapping radon inside the rock/soil interstices. At Terra Nova Bay, the permafrost is $30-60 \mathrm{~cm}$ deep below the surface [26]. Influence from rock and soil geochemistry on radon emanation fluxes was evaluated by radiochemical characterization of surface and deep rock samples from the ice-free areas surrounding the Italian base. Gamma 
spectrometry allowed the determination of the $\gamma$ lines from the ${ }^{238} \mathrm{U}$ and ${ }^{232} \mathrm{Th}$ families connected with the ${ }^{222,220} \mathrm{Rn}$ emanation; results are presented in Table II.

Terra Nova Bay area is characterized primarily by the presence of granites and granodioritic rocks [27], often enriched in radioelements from the uranium and thorium series, as a result of geochemical redistribution processes. The high ${ }^{40} \mathrm{~K}$ levels found reflect the alkaline nature of these rocks. Yet, the activity values of natural radionuclides found in the local samples are not high [28]. This observation suggests a limited contribution from the bedrock of the area to the emanation of radon to the lower troposphere. All the data collected confirm the values reported in past work by the authors for soils, rocks, and lake sediments from Terra Nova Bay [29].

Consistency of radon results can be inferred by the agreement and consequent homogeneity of data from one campaign to the other. Mean values for ${ }^{222} \mathrm{Rn}$ are respectively $0.54 \pm 0.42 \mathrm{~Bq} \mathrm{~m}^{-3}$ in the $95-96$ campaign, $0.50 \pm 0.46 \mathrm{~Bq} \mathrm{~m}^{-3}$ in $96-97$ and $0.48 \pm 0.43 \mathrm{~Bq} \mathrm{~m}^{-3}$ in the $97-98$ campaign. Their consistency has been further confirmed by the data collected in the 1999-2000 campaign, when an updated version of the radon equipment was used. Deviations from one campaign to another are within the experimental uncertainty associated with the method. It is to note that the latter equipment, differently from the formerly used, was directly calibrated according to the procedure mentioned in the experimental section of this paper. Frequency distribution of ${ }^{222} \mathrm{Rn}$ and ${ }^{220} \mathrm{Rn}$ reported in Fig. 3 shows that both radionuclides are not normally distributed, as expected for major atmospheric species concentration [30],

TABLE II Natural radioactivity $(\mathrm{Bq} / \mathrm{kg})$ in soil/rocks samples from BTN

\begin{tabular}{lccccccr}
\hline Campaign 1996-97 & \multicolumn{3}{c}{ U-238 Family } & & Th-232 Family & Primordial \\
\cline { 2 - 3 } Sample & $R a-226$ & Bi-214 & $P b-214$ & & $P b-212$ & $T l-212$ & \\
\hline Perm.B & 23 & 19 & 21 & & 42 & 39 & K-40 \\
Perm.X & 29 & 23 & 25 & & 68 & 63 & 1845 \\
BC6-A & 26 & 19 & 21 & & 45 & 41 & 794 \\
BcG & 22 & 19 & 21 & & 62 & 58 & 1174 \\
AC (SUD b) & 21 & 14 & 15 & & 31 & 29 & 808 \\
Baxter & 25 & 21 & 22 & & 38 & 36 & 1045 \\
\hline
\end{tabular}

$\mathrm{Rn}-222$

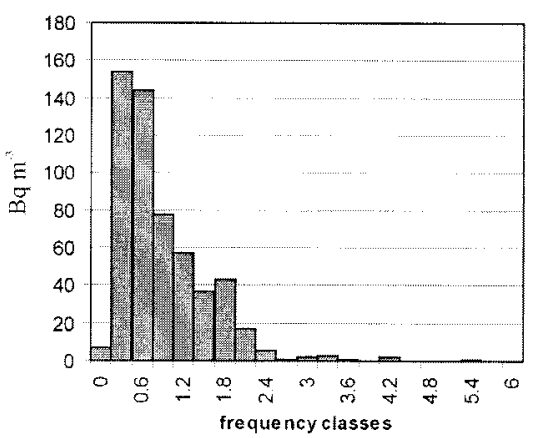

$\operatorname{Rn}-220$

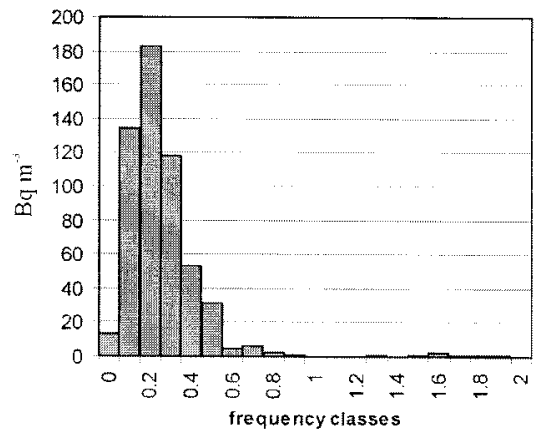

FIGURE 3 Frequency distribution of ${ }^{222} \mathrm{Rn}$ and ${ }^{220} \mathrm{Rn}$. 
therefore, the arithmetic mean values reported through this paper should be taken with special consideration on account of this asymmetrical distribution.

Table III shows mean values of radon isotopes recorded at Terra Nova Bay for the summer periods along with mean values recorded at the Brazilian station of Ferraz located in the South Shetland Islands, Antarctic Peninsula (Fig. 1). Radon data in the lower atmosphere are somewhat lower in Ferraz. This can, in part, be explained by the fact that Ferraz's data set is much larger and includes data collected during the whole year [32-35]. On the other hand, data collection for Terra Nova are restricted to the summer time, when the area free of ice and snow cover is at its maximum, as well as the expected radon flux to the atmosphere. This fact alone, however, cannot account for the higher mean concentration of radon measured at Terra Nova compared to Ferraz, since the seasonal fluctuation of radon at Ferraz is relatively small and does not show a consistent trend (unpublished data by the authors). In contrast with Terra Nova, advection of continental radon from South America is the prevailing parameter controlling the atmospheric radon fluctuation in Ferraz rather than the variation of the local ice-free area. Ferraz station is located on an island and thus has a much smaller exposed area for radon emanation [36]. Results for both stations show that they are at least one order of magnitude lower than the mean continental values for surface atmospheric radon, as reported in literature [24].

For sake of completeness, the above data are compared to other radon values recorded in the Southern Hemisphere as reported in Table IV. Note that the concentrations of radon consistently decrease with increasing latitudes, attaining its minimum value at the South Pole, with values lower than the mean reported for the oceans. Nonetheless, the mean result found for Terra Nova Bay is higher than it should be expected by this simple meridional trend. In fact, it is comparable to that found at lower latitudes such as at a sampling site located in Punta Arenas, South of Chile, employing the same radon measuring equipment and calibration procedures.

In principle, radon concentrations measured in the atmosphere are strongly influenced by meteorological factors that may act either on its diffusive fluxes and/or on its atmospheric concentration [1,31]. Macroscopic features of radon trend in the summer can be summarized as follows: a positive correlation between radon and temperature and a negative correlation with atmospheric pressure as expected.

TABLE III Mean, minimum, maximum activity of ${ }^{222} \mathrm{Rn}$ and ${ }^{220} \mathrm{Rn}\left(\mathrm{Bq} \mathrm{m}^{-3}\right)$ at Terra Nova Bay (1997-98, summer) and at Ferraz (1997, 1998 - complete annual series)

\begin{tabular}{lcll}
\hline & $R n-222$ & $R n-220$ & \\
\hline Terra Nova Bay & Minimum & 0.008 & 0.016 \\
(summer 97-98) & Mean & 0.479 & 0.162 \\
& Maximum & 2.739 & 1.223 \\
& $\sigma$ & 0.429 & 0.132 \\
Ferraz (1997) & Minimum & 0.004 & 0.017 \\
& Mean & 0.160 & 0.119 \\
& Maximum & 2.38 & 0.354 \\
& $\sigma$ & 0.14 & 0.049 \\
Ferraz (1998) & Minimum & 0.005 & 0.017 \\
& Mean & 0.156 & 0.120 \\
& Maximum & 1.842 & 2.525 \\
& $\sigma$ & 0.144 & 0.077 \\
\hline
\end{tabular}


TABLE IV Activity of ${ }^{222} \mathrm{Rn}\left(\mathrm{Bq} \mathrm{m}^{-3}\right)$ in the atmosphere in the southern hemisphere

\begin{tabular}{lccc}
\hline Site & Latitude & Longitude & ${ }^{222} R_{n}\left(\mathrm{~Bq} \mathrm{~m}^{-3}\right)$ \\
\hline Punta Arenas & $53.1^{\circ} \mathrm{S}$ & $071.9^{\circ} \mathrm{W}$ & 0.69 \\
Terra Nova Bay* & $74.69^{\circ} \mathrm{S}$ & $164.12^{\circ} \mathrm{E}$ & 0.51 \\
Cape Grim & $40^{\circ} \mathrm{S}$ & $144.7^{\circ} \mathrm{E}$ & $0.5-1.7$ \\
Ferraz & $62.08^{\circ} \mathrm{S}$ & $58.38^{\circ} \mathrm{W}$ & 0.11 \\
Mcquarie Island & $54.5^{\circ} \mathrm{S}$ & $159^{\circ} \mathrm{E}$ & $0.05-0.2$ \\
Oceans & Average & Average & 0.04 \\
Kerguelem Island & $49.5^{\circ} \mathrm{S}$ & $070^{\circ} \mathrm{E}$ & 0.04 \\
Dumont d'Urville & $66.7^{\circ} \mathrm{S}$ & $140^{\circ} \mathrm{W}$ & 0.025 \\
Molodesnaya & $67.7^{\circ} \mathrm{S}$ & $045.8^{\circ} \mathrm{W}$ & 0.022 \\
Georg Neumayer & $70.6^{\circ} \mathrm{S}$ & $8.36^{\circ} \mathrm{E}$ & 0.02 \\
Mawson & $67.58^{\circ} \mathrm{S}$ & $062.9^{\circ} \mathrm{W}$ & 0.009 \\
South Pole & $90^{\circ}$ & 0 & $0.007-0.015$ \\
\hline
\end{tabular}

*summer data only.

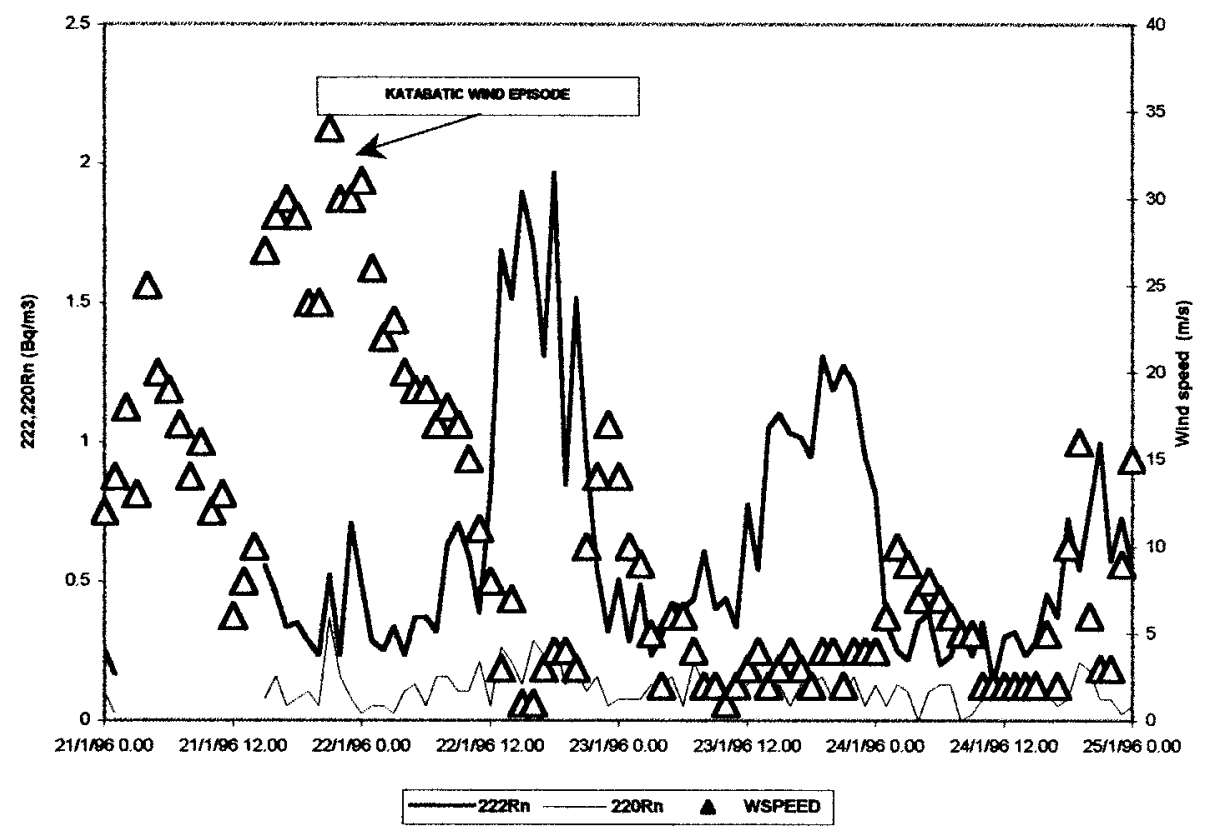

FIGURE 4 Effect of katabatic winds on radon concentration at Terra Nova Bay, episode recorded during the 1995-96 summer campaign.

Another basic feature visible in all time series is the remarkable radon decrease during episodes of katabatic winds, very frequent and active at Terra Nova Bay [18]. These winds are caused by gravity flow of extremely cold air mass sliding down from the elevated inner regions to coastal areas, where it may result further accelerated by a channelling effect through the glacier valleys in the area. During these events, atmospheric radon concentration is strongly reduced either by the extreme dispersion effect caused by the wind or by dilution with radon-depleted air masses. An example of the effect of katabatic winds on ${ }^{222} \mathrm{Rn}$ concentration is shown in Fig. 4. 
Our results show that radon measured at Terra Nova Bay is mostly produced locally by emanation from ice-free areas, as revealed by the presence of the short-lived ${ }^{220} \mathrm{Rn}$ (thoron) systematically recorded in the alpha spectra. Its half-life of $56 \mathrm{~s}$, in fact, does not allow its survival beyond a few meters from its emission site. For all the available data collected at Terra Nova Bay in three campaigns a mean ${ }^{222} \mathrm{Rn}$ to ${ }^{220} \mathrm{Rn}$ ratio of $4.4 \pm 4.2$ was calculated (minimum $=0.1$; maximum $=45.3$ ). Highest values of radon isotopic ratios suggest the possible advection of ${ }^{220} \mathrm{Rn}$-depleted air masses over Terra Nova Bay, i.e. of non local origin, as reported e.g. in Fig. 5.
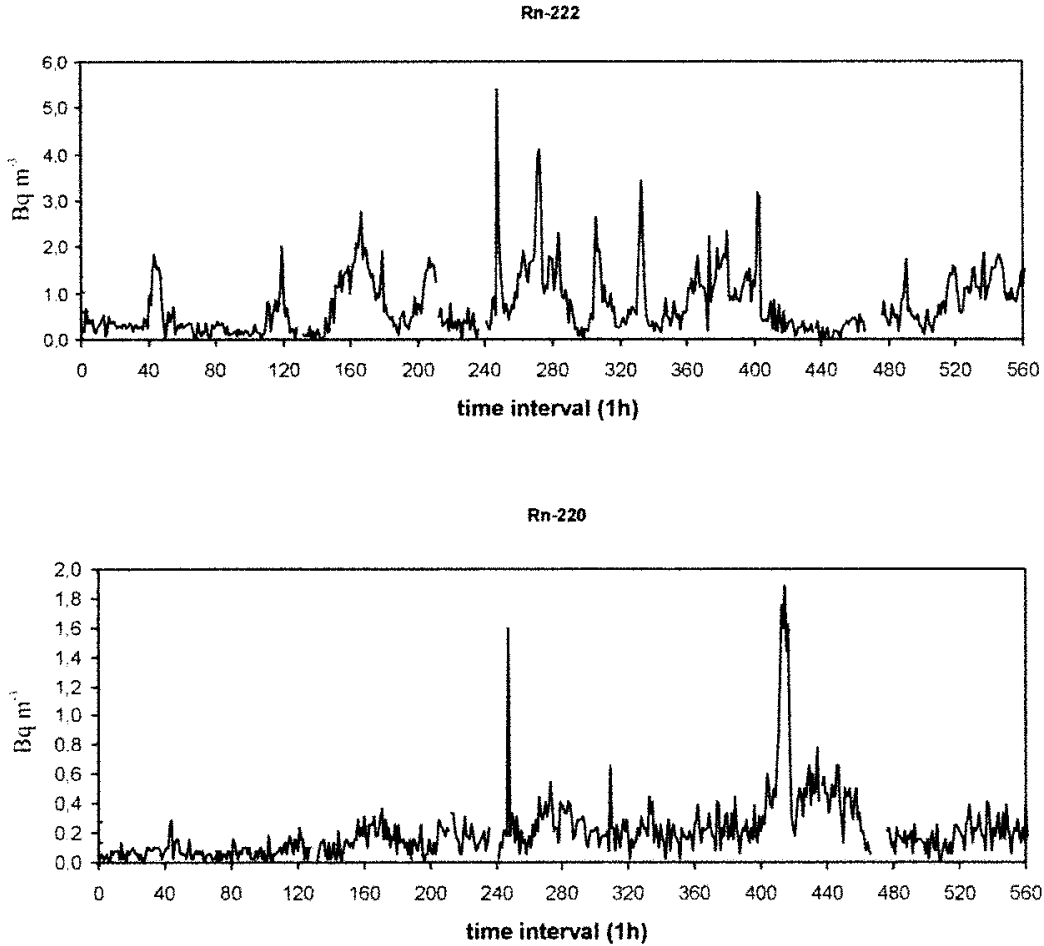

$\mathrm{Rn}-222 \mathrm{Rn}-\mathbf{2 2 0}$

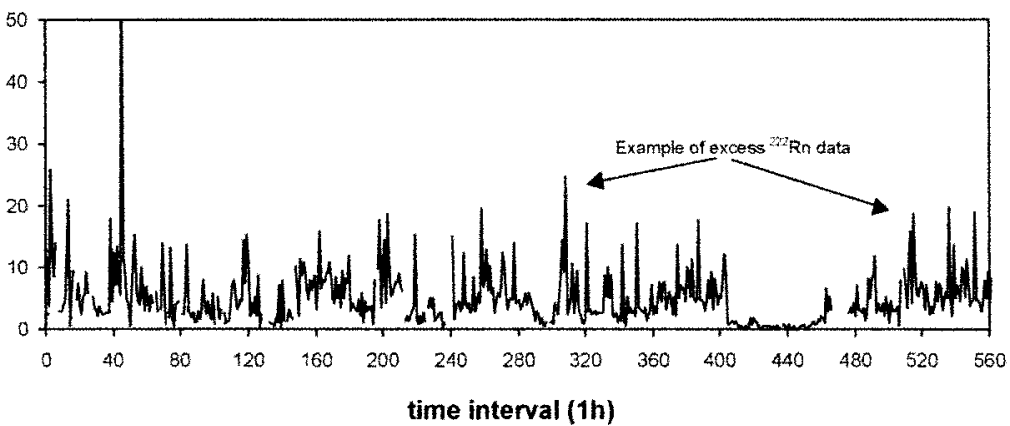

FIGURE $5{ }^{222} \mathrm{Rn},{ }^{220} \mathrm{Rn},{ }^{222} \mathrm{Rn} /{ }^{220} \mathrm{Rn}$ ratio time-series in $1997-98$ summer expedition. In the diagram excess ${ }^{222} \mathrm{Rn}$ values and consequent highest isotopic ratios are highlighted. 
Influence of permafrost over radon flux has not yet been evaluated at Terra Nova Bay. Based on the results obtained for Ferraz it is possible to infer that both places share many similar geomorphological and climatic features. During summer, the absence of the ice and snowcap and the increase in solar irradiation cause an increase in the skin temperature of the terrain with respect to the temperature at the permafrost level. This process inhibits the convective flow of energy and mass to the surface. This effect should also reduce the emission of radon at the soil-atmosphere interface. Nevertheless, the role played by this effect in the net radon emission is yet unknown at Terra Nova Bay and may be a cause of the comparatively higher radon concentration.

Differently from other stations in Antarctica, radon at BTN shows a small amplitude daily fluctuation as it is usually observed at lower latitude continental sites (Fig. 6). This feature is associated to the small but existing diurnal oscillation of the sun above the horizon, observed by Bromwich et al. [18] even for meteorological parameters. This affects the heating of the rocky outcrops in the BTN area and, consequently, radon fluxes.

Correlation between radon data and wind direction has been therefore, studied. Radar-type diagrams of radon mean concentration versus wind direction pointed out on one side the huge decrease in both isotopes in connection with the katabatic winds from the inner continent $\left(270^{\circ}\right)$. Directionality of ${ }^{222} \mathrm{Rn}$ data in contrast with ${ }^{220} \mathrm{Rn}$ is clearly seen in Fig. 7, for the data 1997-98. Data from the previous campaigns collected over shorter periods, and therefore, statistically less reliable, show less convincing patterns. It is to note ${ }^{222} \mathrm{Rn}$ peak around $60^{\circ}$, i.e. from the Ross Sea, from where wind is not very frequent compared to other directions [16], see also the rose wind in Fig. 8. This finding suggests the advection of air masses from outside Terra Nova Bay area at distances such as to allow total decay of ${ }^{220} \mathrm{Rn}$ during the transit over

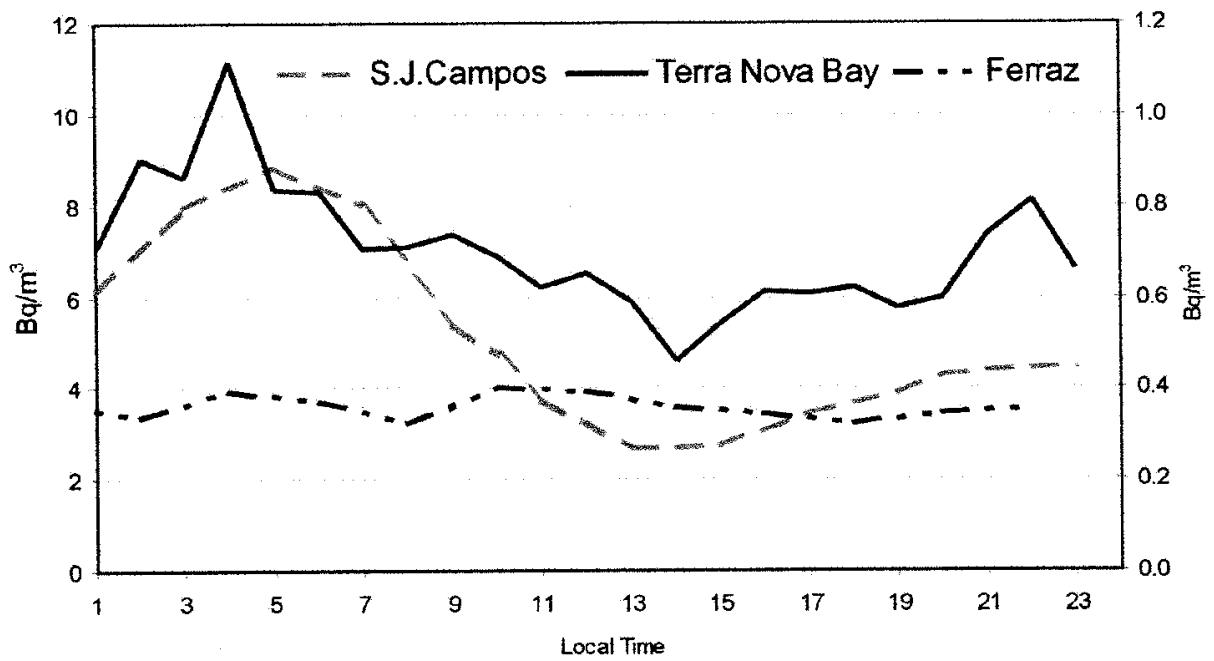

FIGURE 6 Daily concentration profile of radon in Terra Nova as compared to profiles obtained with the same technique in sites located at higher latitudes. Values on the principal $Y$ axis on the left are referred to data collected in S.Josè dos Campos, while the secondary $Y$ axis is referred to Antarctic data (Terra Nova Bay and Ferraz). 


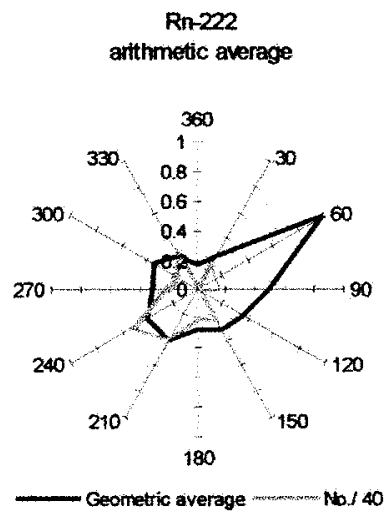

Rn-222

arithmetic average

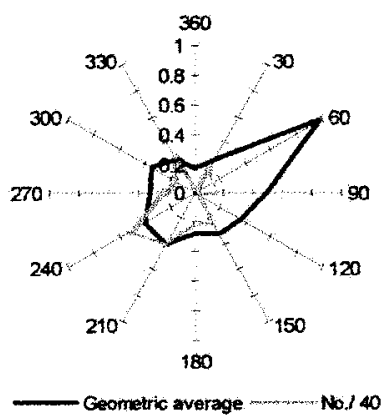

Rn-220

anithmetic average

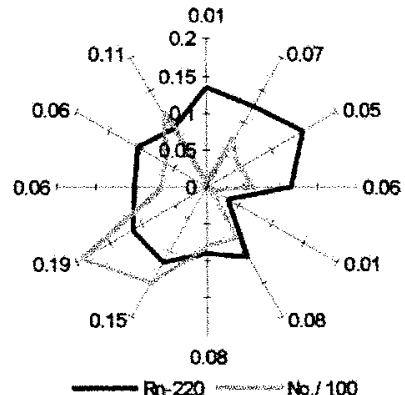

Rn-220

anthmetic average

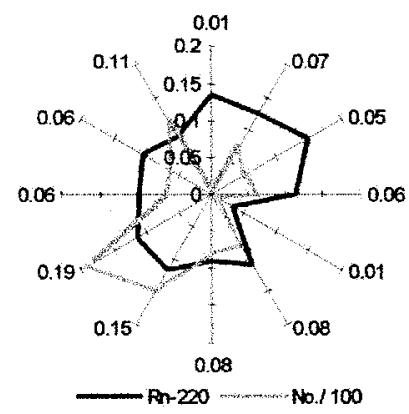

FIGURE 7 Radar diagrams for ${ }^{222} \mathrm{Rn},{ }^{220} \mathrm{Rn}$ activities and frequencies in association with geographical origin. Radon data refer to $1997-98$ summer campaign.

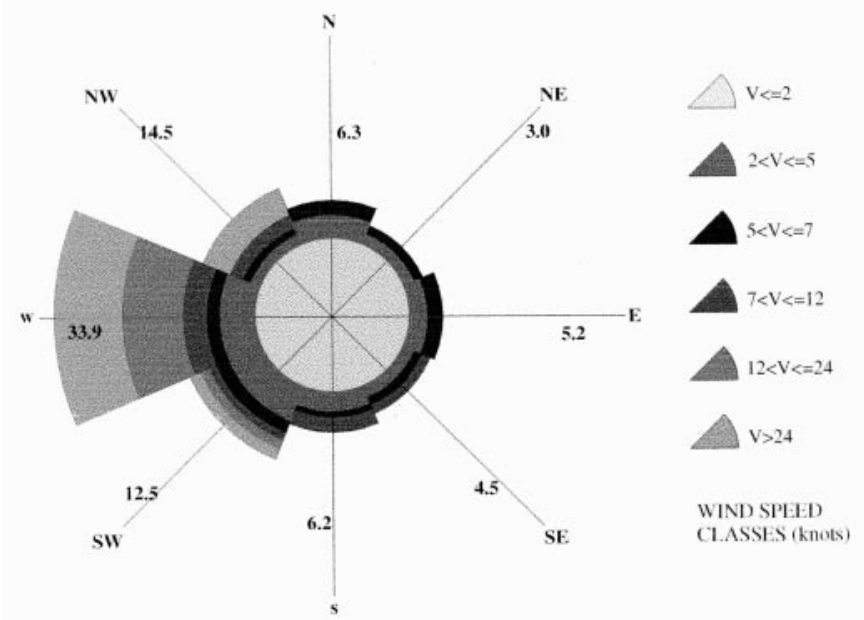

FIGURE 8 Rose wind for the Automated Weather Station Eneide at Terra Nova Bay. 
the ocean. Origin of this inflow is under investigation, though three sources could be pointed out:

(a) enhanced local production of radon - although this is not positively supported by the available radiometry of local soil samples, the comparative daily radon oscillation shown in Fig. 6 indicates that the time pattern observed for Terra Nova Bay area is similar to that found for a site located in Brazil using the same measuring technique. Over the ice-free continental area in lower latitudes, such as in Brazil, the ground source of radon is unequivocal and the general daily fluctuation displays a characteristic well-described increase of radon during the night, followed by a decrease during the day. This is caused by the expansion of the planetary boundary layer due to the surface heating by sunlight. In Ferraz, this fluctuation, if existent at all, is very subtle supporting the evidences shown in a previous work [35] for the minor importance of local source for the radon measured in Ferraz;

(b) long-range radon transport from New Zealand, and possibly Australia, triggered by the frequent and strong cyclonic systems that circulates around Antarctica. This transport mechanism can be very effective such in the case of Ferraz with respect to the source located in South America. However, the distance between the Italian station an New Zealand is over $2500-3000 \mathrm{~km}$ against the $950 \mathrm{~km}$ between the Antarctic Peninsula and South America;

(c) possible influence from the Mt. Erebus, an active volcano located on the Ross Island, near the U.S. station of McMurdo, about $350 \mathrm{~km}$ south of Terra Nova Bay. Rock fracturing, along with warm ground water circulation associated to volcanic activity in and around this volcano, helps deep-seated radon sources outgassing to the atmosphere which could, in principle, lead to a continuous enhancement of radon in the local atmosphere [36-39]. The whole area, lying on the Western Ross Sea, is located over an active rift characterized by the presence of a complex volcanic system known as McMurdo Volcanics, including Mt. Erebus (Ross Island, about $300 \mathrm{~km}$ south of BTN), Mt. Melbourne and Mt. Rittmann. Studies concerning this volcanic region have been carried out by Italian geologists [38], though reference work has been carried out by Kyle et al. [40] in 1989. Roughly speaking, there are at least three volcanoes scattered along a few hundred kilometres along the Western Ross Sea, including Mc Murdo and BTN stations.

Mt. Erebus is presently the only active volcano in this area. It is constantly monitored at MEVO [41] and is presently under close investigation mainly for its impact on the Antarctic atmosphere [42]. All of the other volcanoes are presently dormant. Diffuse fumarolic activity is seen on the top of both Mt. Melbourne and Rittmann. Unfortunately, no assessment of this geothermal activity has been carried out so far. Nevertheless it is relevant to observe that, as far as the Mt. Erebus is concerned, its contribution for airborne radionuclides has long being recognized [43]. Moreover, in a recent compilation of global data of environmental ${ }^{210} \mathrm{~Pb}$, a descendant of ${ }^{222} \mathrm{Rn}$, the discussion concerning ${ }^{210} \mathrm{~Pb}$ in Antarctica excluded the highest value from McMurdo area because, as from the citation of the authors, they were not representative of the continent, owing to ${ }^{210} \mathrm{~Pb}$ contributed by Erebus volcano [44]. Though extrapolation to BTN is not straightforward, we cannot exclude "a priori" this regional effect of local volcanism on the natural airborne radionuclides measured, including that of radon. The diffuse presence of fumaroles in the area might reasonably enhance the activity of radon and of its progeny. Such a "volcanic" fraction, negligible at usual continental levels of 
radon, might contribute to Antarctic radon levels as our data seem to reveal. A similar situation has been reported at Mauna Loa (Hawaii), i.e. a place far off continental emissions as well, where the volcanic contributions are well recognized both in terms of stable species such as carbon dioxide and radionuclides like radon [45].

In addition, the atmospheric circulation is not thoroughly known in the Ross Sea if not for the katabatic component which has been extensively studied by Bromwhich et al. [18]. If we go back to the data discussed in the present paper, two points need to be stressed:

1. Geomorphological observations can give further support to the validity of the data recorded. In fact, though the local rocks did not show high levels of radon precursors, the alkaline granites and granitoids typical of this area, interacting with the permafrost, cause a high degree of fragmentation in the ground so that radon and thoron are set free to exhale from fractures into the atmosphere. The permafrost appears $30-60 \mathrm{~cm}$ below the surface and rock outcrops are rather diffuse in this area where deposited snow is frequently swept away by strong katabatic winds even during the winter. We continuously see thoron in our data.

2. In addition, continuous insolation during the polar summer causes the heating of the dark granitic bedrock leading to observable exhalation of water vapour. No geothermal activity is observed around the base, so that water vapour is related solely to the high thermal capacity of the local rocks [46].

Present information associated to atmospheric circulation, together with past work on radon in this area suggests that peaks of radon depleted in thoron observed at BTN can be attributed to the influence of Mt. Erebus plume.

\section{CONCLUSIONS}

A high-sensitivity, fast response apparatus for measuring atmospheric radon allowed to determine time-series of ${ }^{222} \mathrm{Rn}$ and ${ }^{220} \mathrm{Rn}$ during the 1995-96, 1996-97 and 1997-98 summer campaigns at Terra Nova Bay, Antarctica.

A mean value of $0.51 \mathrm{~Bq} \mathrm{~m}^{-3}$ calculated over the three periods shows a value that is about three times higher than that observed at another Antarctic coastal station, the Brazilian station of Ferraz, where a similar instrument is used. The reasons for this higher value at Terra Nova may be attributed to local sources as well as to the transport from other producing areas. The 24-h cycle, usually detected in ground producing areas, has been observed at Terra Nova Bay suggesting that local sources could be responsible for the higher than expected radon concentration at this latitude. This hypothesis is also supported by the systematic detection of short-lived ${ }^{220} \mathrm{Rn}$ isotope. However, episodic increases of ${ }^{222} \mathrm{Rn}$ not accompanied by corresponding ${ }^{220} \mathrm{Rn}$ variations were also observed. Data analysis associates these events to tropospheric advective transport from the Ross Sea area. A positive correlation was observed between episodes of low radon concentrations and katabatic winds.

\section{Acknowledgements}

This work has been supported by the Italian Program of Research in Antarctica (PNRA) - Environmental Contamination Sector. The authors wish to thank Marcelo 
Sampaio for instrument construction and calibration, and Heitor Evangelista da Silva for helpful discussions and suggestions. The authors are very grateful to Ruggero Lorenzelli of ENEA-Brasimone for his invaluable help in the field operation of the 1997-98 campaign and to Paolo Grigioni and Andrea Pellegrini of ENEA-Casaccia for providing meteorological data from the AWS Eneide database.

\section{References}

[1] R. Reiter, Atmospheric Transport Processes - Part 4, Radioactive Tracers. DOE, Colorado State University, Washington D.C., pp. 28-102 (1978).

[2] R.A. Brost, J. Feichter and M. Heimann, J. Geophys. Res., 96(D12), 22423-22445 (1991).

[3] M. Heimann and J. Feichter, GLOMAC Report No. 2, Report No. 8. Meteorologisches Institut, Hamburg (1990).

[4] J.A. Garland, R.S. Cambray and C.E. Johnson, In: C.N. Hewitt and W.T. Sturger (Eds.), Global Atmospheric Chemical Change, London, pp. 380-420 (1993).

[5] H.W. Gäggeler, Radiochimica Acta, 70/ 71, 345-353 (1995).

[6] E.B. Pereira, In: B. Bouville, D. Jacob and M. Prather (Eds.), Proceedings of a WCRP Workshop on the Parameterization of Sub-scale Tracer Transport. Virginia Beach, USA, November 30-December 3, 1993. pp. 81-91. WMO/TD-No. 823, Report No. 26 (1997).

[7] H.E. da Silva, O Emprego do Radonio na Caracterizacao de Fenomenos de Transporte e Impacto Ambiental Atmosfericos na Ilha Rei George (Antarctica). Ph.D. Thesis, 198 pp, State University of Rio de Janeiro, Brazil (1998).

[8] D. Jacob and M. Prather, Tellus, 42B, 118-134 (1990).

[9] J. Feichter and P.J. Crutzen, Tellus, 42B, 100-117 (1990).

[10] C. Genthon and A. Armengaud, J. Geophys. Res., 100(D2), 2849-2866 (1995).

[11] G. Lambert, B. Ardouin and B. Sanak, Tellus, 42B, 76-82 (1990).

[12] M. Heimann, P. Monfray and G. Polian, Tellus, 42B, 83-99 (1990).

[13] E.B. Pereira, Tellus, 42B, 39-45 (1990).

[14] C. Genthon and A. Armengaud, Sci. Tot. Environ., 160/161, 101-116 (1995).

[15] D.H. Bromwich and T.R. Parish, Antarctica: barometer of climate change. Report to the National Science Foundation from the Antarctic Meteorology Workshop, Madison, Wisconsin (USA) (June 1998).

[16] ANT 89/8, Baia Terra Nova, Mare di Ross: Caratterizzazione Ambientale. ENEA, Roma (1989).

[17] M. Colacino, E. Piervitali and P. Grigioni, In: Faranda, Guglielmo and Ionora (Eds.), Ross Sea Ecology. Springer-Verlag, Berlin Heidelberg, pp. 15-26 (2000).

[18] D.H. Bromwich, T.R. Parish, A. Pellegrini, C.R. Stearns and G.A. Weidner, In: D.H. Brombich and C.R. Steams (Eds.), Antarctic Research Series, Vol. 61, pp. 47-68 (1994).

[19] E.B. Pereira and H.E. da Silva, Nucl. Instr. Methods, A280, 503-505 (1989).

[20] M.G. Bettoli, L. Cantelli, D. Capra, L. Tositti and O. Tubertini, Proceedings 5th National Conference PNRA - Environmental Contamination, 11-12 February 1997, Venice, Italy, pp. 26-31 (1991).

[21] E.B. Pereira, P.L.S. Dias and D.J.R. Nordemann, Revista Brasileira de Geofiisica, 9, 61-68 (1991).

[22] H. Evangelista, H.M. Fernandes, E.B. Pereira and M. Sampaio, J. Radiation Protection Dosimetry, 98, 235-238 (2001).

[23] E.B. Pereira, E.H. Silva and M.P. Souza, Anais do V Seminário sobre Pesquisa Antártica, Ed. Instituto de Geociências/USP, São Paulo, Brazil, October, 16-17, pp. 13-14 (1997).

[24] UNSCEAR, Sources and Effects of Ionizing Radiation, United Nations, New York, pp. 89 (1993).

[25] A.A. Jarret, Statistical Methods used in the Measurement of Radioactivity. US Atomic Energy Commission, Oak Ridge National Laboratory Technical Information Service, AECU-262, June 17, Oak Ridge, USA, 61 pp. (1946).

[26] M. Guglielmin, pers. comm.

[27] C. Baroni, Mem. Soc. Geol. It., 33, 195-211 (1987).

[28] M. Eisenbud and T. Gesell, Environmental Radioactivity from Natural, Industrial, and Military Sources, Academic Press, San Diego, pp. 656. (1997).

[29] M.G. Bettoli, L. Tositti, O. Tubertini and L. Cantelli, Ann. Chim., 79, 735-742 (1989).

[30] Istituto Nazionale di Statistica, Metodi di analisi statistica dei dati di qualità dell aria, Metodi e norme serie $B n^{\circ} 30$, ISTAT, Roma, pp. 164 (1997).

[31] J. Porstendörfer, J. Aerosol Sci., 2, 219-263 (1994).

[32] E.B. Pereira, D.J.R. Nordemann and M.B.A. Vasconcellos, Anais da Academia Brasileira de Ciências, 58, 181-186 (1986).

[33] E.B. Pereira, A.W. Setzer and I.F.A. Cavalcanti, Rad. Prot. Dosimetry, 24, 85-88 (1988)

[34] E.B. Pereira, Tellus, 42(B), 39-45 (1990). 
[35] E. Evangelista and E.B. Pereira, Produção e fluxos de radonio na interface solo-atmosfera da Ilha Rei George. Anais do VII Seminário sobre Pesquisa Antártica, São Paulo, p. 17, Centro de Pesquisas Antárticas/USP, novembro de 1999, Journal of Environmental Radioactivity. 61, 283-304 (2002).

[36] C.A. Ricci (Ed.), Proceedings of the Meeting Earth Science Investigations in Antarctica. Mem. Soc. Geol. It., 46, 610 (1991).

[37] A.R. Smith, H.R. Bowman, D.F. Mosier, F. Asaro, H.A. Wollenberg and Chi-Yu King, Proceedings of the IEEE Nuclear Science Symposium, San Francisco, USA, November 19-21, REPORT LBL-4445 (1975).

[38] P. Gasparini and M.S.M. Mantovani, J. Volcan. Geotherm. Res., 3, 325-341 (1978).

[39] E.B. Pereira and V. Hamza, Revista Brasileira de Geofisica, 1, 37-44 (1982).

[40] P.R. Kyle. In: W. LeMasurier and J. Thompson (Eds.), Volcanoes of the Antarctic Plate and Southern Oceans, AGU Antarctic Research Series, Vol. 48, American Geophysical Union, Washington D.C., pp. 19-139 (1990).

[41] (http://www.ees.nmt.edu/Geop/erebus.html)

[42] G. Zreda-Gostynska, P.R. Kyle, D. Finnegan and K.M. Prestbo, J. Geophys. Res. 102(B7) 15039-15055 (1997).

[43] G. Polian and G. Lambert, J. Volcan. Geother. Res., 6, 125-137 (1979).

[44] N. Preiss, M.A. Mélières and M. Pourchet, J. Geophys. Res, 101(D22), 28847-28862 (1996).

[45] S. Whittlestone, S.D. Schery and Y. Li, J. Geophys. Res. 101(D9), 14787-14794 (1996).

[46] P. Armienti, Pers. Comm. 